\title{
REGULAÇÃO E CONCORRÊNCIA NA SEARA NOTARIAL
}

\author{
REGULATION AND NOTARIAL COMPETITION
}

\section{Rogerio Mollica}

Mestre e Doutor em Direito Processual pela Universidade de São Paulo. Professor dos Programas de Mestrado e Doutorado em Direito da Universidade de Marília - Unimar.

Email: rogerio@ caisadvogados.com.br

\section{Olavo Figueiredo Cardoso Junior}

\begin{abstract}
Bacharel em Comunicação Social pela PUC-RJ. Bacharel em Direito pela PUC-RJ. Especialista em Direito Constitucional pela Universidade Estácio de Sá-RJ. Mestre em Direito pela Escola Paulista de Direito-SP. Mestre em Direito pela UNIMAR-SP. Doutorando em Direito pela UNIMAR-SP. Doutorando em Direito pela FADISP-SP. Ex-corretor de imóveis. Ex-advogado. Tabelião de Notas e de Protesto de Títulos em Marília-SP. E-mail: protestonotas@gmail.com
\end{abstract}

Recebido em: 28/08/2019

Aprovado em: 27/05/2020

RESUMO: O presente artigo abordou a regulação e a concorrência notarial. Para tanto, teve-se como objetivo principal descrever o regramento incidente sobre a atividade e a concorrência existente entre os tabeliães de notas, e, para tanto, inicialmente contextualizou-se o aspecto histórico, econômico e legal da concorrência, de forma a esclarecer o leitor sobre a importância da preservação desta prática como forma salutar de incentivo à melhora constante de seus serviços, sendo a sociedade a maior beneficiária. Na sequência, explicou-se a regulação e a concorrência dos serviços notariais brasileiros, as quais assumem uma característica especial pelo fato que não vigem no tabelionato brasileiro o sistema de livre iniciativa, já que eles exercem atividade jurídica. Podese afirmar que, embora a atividade seja exercida com finalidade lucrativa, isso não é o suficiente para caracterizá-la como uma atividade empresarial, podendo-se afirmar que, neste cenário, reina uma realidade de oligopólio, onde vários tabeliães disputam entre si o cliente, mas com as mesmas restrições em relação às comarcas onde atua somente um profissional. O princípio metodológico adotado para elaboração do presente artigo foi a de pesquisas em materiais secundários compostos por livros, trabalhos acadêmicos científicos e legislação pertinente ao tema, possibilitando responder o objetivo proposto. Pode-se chegar à conclusão que, ainda que haja inúmeras restrições para que a concorrência notarial possa ser exercida, é possível ao tabelião se destacar dos demais, dando concretude ao princípio da livre escolha do tabelião, dentro das regras existentes, sem praticar nenhuma ilicitude tal como a adoção de estratégias mercadológicas ou redução de emolumentos, como costumam fazer alguns maus tabeliães.

Palavras-chaves: concorrência, notarial, tabelião.

ABSTRACT: The present article dealt with the regulation and notarial competition. In order to do so, the main objective was to describe the regulation on activity and competition among notaries and, for that, initially the historical, economic and legal aspect of the competition was initially contextualized so as to clarify the reader about the importance of preserving this practice as a 
salutary form of encouraging the constant improvement of its services, with society being the largest beneficiary. In the sequence, it was explained the notarial regulation and competition, which assumes a special characteristic for the fact that the system of free initiative does not operate in the brazilian notarial services, since they exercise legal activity and, although they do it for profit, this is not enough To characterize it as a business activity, and it can be said that in this scenario a reality of oligopoly reigns, where several notaries compete among themselves for the client, but with the same restrictions in relation to the regions where only one professional operates. The methodological principle adopted for the elaboration of the present article was the research of secondary materials composed of books, academic scientific works and legislation pertinent to the subject, making possible to answer the proposed objective. It can be concluded that, although there are numerous restrictions for notarial competition can be exercised, it is possible for the notary to stand out from the others, giving concrete form to the principle of free choice of notary, within the existing rules, without practicing any unlawfulness such as the adoption of marketing strategies or the reduction of fees, as some bad notaries usually do.

Keywords: competition, notarial, notary.

SUMÁRIO: Introdução. 1. Concorrência; 2. Regulação e Concorrência Notarial; 2.1. Regulação Notarial, Classificação e Sistema Concorrencial do Notariado Brasileiro; 3. Exercício da Concorrência Notarial; Conclusão; Referências.

\section{INTRODUÇÃO}

A ordem econômica, consagrada constitucionalmente no Brasil, legitima como um de seus princípios, a livre iniciativa. Esta, por sua vez, desdobra-se na livre concorrência e liberdade de comércio e indústria.

A concorrência constitui-se de um fenômeno complexo e a liberdade é um de seus pressupostos principais. Trata-se de um instrumento fundamental para que indivíduos, empresários e investidores, entre outros, possam utilizar sua intelectualidade da melhor forma possível, com o fim de organizar a produção de bens de consumo e/ou prestação de serviços, visando, sempre, fabricar produtos e oferecer serviços de qualidade a um preço cada vez mais competitivo.

Oportuna, nesse aspecto, a doutrina de Souza (2016, p. 216), que ensina:

[...] é através da livre concorrência que as empresas melhoram suas condições de competitividade e são forçadas a aprimorar sua tecnologia, qualidade e custos, oferecendo assim, condições mais favoráveis ao consumidor, funcionando como uma mola propulsora da economia de mercado.

Nesse contexto, cabe ainda salientar a existência de estruturas mercadológicas nas quais a concorrência se estabelece, e cuja avaliação está no tamanho e na capacidade das empresas em influenciar a definição dos preços de produtos disponíveis no mercado, podendo-se citar: concorrência monopolística; oligopólio; duopólio; oligopsônio; monopólio; monopólio natural, e monopsônio.

Em teoria, os indivíduos são livres para consumir e produzir o que desejar. Mesmo que o livre comércio constitua um direito social, não quer dizer que possa causar prejuízo à interesses sociais ou a outros indivíduos. Assim sendo, a liberdade de concorrência é substancial, já que tem como função impedir ou dificultar a utilização indevida do poder econômico.

$\mathrm{O}$ texto constitucional impõe limites e determina objetivos para o desempenho da atividade econômica, a qual deve ser praticada de forma a promover a justiça social, preservar a 
dignidade da pessoa humana e se nortear pelo cumprimento dos princípios constitucionais, com relevo para a livre concorrência.

Cabe ainda lembrar o regramento legal que regulamenta o Direito de Concorrência. Até novembro de 2011, era a Lei n. ${ }^{\circ}$ 8.884/1994, e atualmente, o Sistema Brasileiro de Defesa da Concorrência é sustentado pela Lei n. ${ }^{\circ} 12.529 / 2011$, responsável por prevenir e reprimir infrações cometidas contra a ordem econômica do país.

Esclarecidos os vieses mercadológicos e legais da concorrência, tem-se que a competição entre os tabeliães de notas deva ser pautada na lealdade e reconhecimento de seu preparo e capacidade profissional, de maneira que não comprometa o prestígio e a dignidade das funções exercidas e das instituições notariais.

Assim, será objetivo do presente estudo avaliar a questão concorrencial na seara notarial, avaliando o regramento legal pelo qual devem se pautar os tabelionatos, de forma que a concorrência possa ser exercido entre estes profissionais de forma ética e moral, avaliando quais práticas para atração de clientes seriam aceitáveis ou repreensíveis.

O princípio metodológico adotado para elaboração do presente artigo foi a de pesquisas em materiais secundários compostos por livros, trabalhos acadêmicos científicos e legislação pertinente ao tema, possibilitando responder o objetivo proposto.

\section{CONCORRÊNCIA}

As atuais e significativas mudanças que o mercado global vem sofrendo são efeitos da crescente relevância que os Estados vêm atribuindo à conjuntura econômica atual. Alguns dos indicativos dessas mudanças são o desenvolvimento acelerado da tecnologia e a concentração de poder econômico, evidenciando, assim, a necessidade de uma abordagem distinta do presente contexto.

O fenômeno da concorrência é algo a ser destacado nesse cenário, podendo ser definido como uma situação em que

[...] distintos agentes econômicos disputam a entrada, manutenção ou predomínio num mercado, definido por serviços ou produtos que sejam iguais ou substituíveis entre si, definido ainda pela efetividade dessa disputa num espaço geográfico e temporal determinado (ASCENSÃO, 2002, p. 87).

A respeito da tradicional concepção de concorrência, Vaz (1993, p. 27) diz o seguinte:

A noção tradicional de concorrência pressupõe uma ação desenvolvida por um grande número de competidores, atuando livremente no mercado de um mesmo produto, de maneira que a oferta e a procura provenham de compradores ou de vendedores cuja igualdade de condições os impeça de influir, de modo permanente ou duradouro, no preço dos bens e serviços.

A concorrência, por assim dizer, é um fenômeno complexo e a liberdade é um de seus principais pressupostos, pois ela é fundamental para que pessoas ligadas a esse universo, empresários e investidores, por exemplo, possam utilizar de sua intelectualidade da melhor forma possível para organizar a produção de bens de consumo e/ou prestação de serviços, visando, sempre, fabricar produtos de qualidade e comercializá-los no mercado a um preço que atraia o consumidor (BARBOSA, 2011).

Por conseguinte, a existência de um número muito grande de empreendedores visando o mesmo tipo de consumidor, produzindo e/ou comercializando de mercadorias parecidas ou iguais, é a condição básica para que a concorrência ocorra. Além disso, para que ela de fato se estabeleça, 
é preciso que a concorrência aconteça em espaço e tempo comuns, tendo por objeto a disputa de uma mesma base de clientes.

Partindo de uma perspectiva histórica, vê-se que a concorrência se torna um fenômeno relevante nos países continentais, em especial, após a Segunda Guerra Mundial. Criava-se a expectativa de que a unificação econômica dos países europeus, estabelecida após a guerra, resultasse no exercício do livre mercado, suprimindo impedimentos burocráticos e legislativos determinados pelo Estado. No entanto, concomitantemente, mantinha-se um pé atrás quanto à livre iniciativa, no que diz respeito ao seu exercício abusivo e possíveis efeitos negativos. É nesse contexto social de integração da europeia, portanto, que a concorrência assume e passa a desempenhar uma função importante no mercado global (BERNINI, 1991). A competição, sendo um mecanismo natural de limitação do poder econômico do empresariado, é tomada como instrumento fundamental para o progresso econômico da União Europeia. É importante perceber que nações vinculadas à Civil Law assumiram, exatamente, ao Common Law, um antitruste de veto da política local. Segundo Silva (2010), isso promoveu um alinhamento jurídico-econômico entre os EUA e a Europa.

Dessa forma, é sob condições de crescente complexidade que o direito econômico da sociedade globalizada se alarga. Simultaneamente, verificava-se uma crise na regulação do direito estatal, criticado frequente por não se adaptar às possibilidades de escolha e de ação criadas pelo progresso tecnológico, e por uma difusão nos modos de produção do direito, que evoluíram para adotar perfis autorregulativos e policêntricos. Esse fenômeno é tido pela filosofia do direito como resultante de uma gradual troca da "pirâmide" normativa kelseniana por estruturas normativas descentralizadas, ordenadas de forma emaranhada, semelhantemente a "teias de aranha", e determinadas somente para estabelecer proposições para resoluções flexíveis. Devido a isso, o pluralismo jurídico é retomado por grande parte da teoria do direito (CAMPILONGO, 2000).

É importante, ainda, atentar para as estruturas de mercado em que a concorrência se estabelece, cuja avaliação está no tamanho e na capacidade das empresas de influenciar na definição de preços de produtos disponíveis no mercado. Logo, o mercado se estrutura da seguinte forma:

Concorrência monopolística: também chamada de competição monopolística, é um tipo de concorrência imperfeita. Consiste numa estrutura industrial em que diversas organizações adversárias comercializam mercadorias semelhantes, mas que não se substituem perfeitamente. Ou seja, vários fabricantes produzem produtos distintos, os quais podem se substituíveis um pelo outro, sendo passível uma concorrência, não havendo um vero monopólio e nem uma situação de concorrência perfeita. As mercadorias concorrentes podem, em diversos aspectos, assemelharem-se, mas existirá sempre um aspecto que as distingue em termos de qualidade, ou aparência, sendo cada empresa a única fornecedora de seu artigo ou serviço. (FRANK; BERNANKE, 2012).

Oligopólio: são setores do mercado que apresentam poucas organizações atuantes, encontrando-se entre os dois extremos de concorrência: a do monopólio e a perfeita. A principal característica dessa forma de mercado é a dificuldade de entrada no mercado, assim como no monopólio. Para que o oligopólio se efetive, em geral, é preciso dificultar a entrada de novas organizações concorrentes. É classificado como oligopólio homogêneo quando a mercadoria vendida pelas organizações que atuam nesse tipo de mercado é muito similar e respeita um padrão. Logo, uma organização não pode vender sua mercadoria por um preço muito diferente das demais, pois, caso contrário, correria o risco de perder clientes. Por outro lado, é denominado oligopólio diferenciado quando existe uma maior diferenciação entre as mercadorias oferecidas pelas organizações (GOLÇALVES, 2012).

Duopólio: trata-se de um setor do mercado que possuí duas organizações atuantes apenas. De maneira simplificada, estruturalmente permite que duas organizações sejam iguais em demandas e custos. Ademais, as organizações podem optar por respeitar o preço padrão ou por 
reduzir demasiadamente o preço de seu produto a ponto de falir sua concorrente, tornando-se única no mercado. O que existe de diferente nessa estrutura é o fato de que para uma organização lucrar ela depende tanto de suas próprias estratégias quanto das estratégias da corrente (SAMUELSON; NORDHAUS, 2012).

Oligopsônio: nesse tipo de estrutura há muito vendedores para poucos compradores. $\mathrm{O}$ setor industrial de laticínios é um exemplo disso. Em grande parte dos municípios, há um pequeno número de indústrias de laticínio que compram grande parte do leite coletado pelos pecuaristas da localidade. A indústria automobilística é um outro exemplo de estrutura de mercado oligopsônio, já que é oligopsonista tanto no mercado de autopeças como no mercado de bens e serviços (FARIAS, 2013).

Monopólio: trata-se de um setor de mercado dominado por uma única organização, pois apenas ela oferece aquele produto ou serviço específico e não existem outras que a substitua. Alguns economistas afirmam que uma organização obtém monopólio quando ela age independente das ações de outras organizações, ou seja, ignorando-as. Dizendo de outra forma, as demais organizações não estarão, provavelmente, produzindo mercadorias substitutas semelhantes ao do monopolista, podendo ele ignorar completamente o preço fixado por essas organizações. As velas, por exemplo, substituem a luz elétrica, porém as empresas que fornecem energia elétrica não precisam se preocupar com quedas nos preços das velas, pois que nenhum consumidor dispensará o uso de luz elétrica e passará a utilizar velas em razão disso. Por conseguinte, uma distribuidora de energia elétrica local é, evidentemente, uma monopolista (HUBBARD; O'BRIEN, 2010).

Monopólio natural: quando as economias de escala estimulam a produção de um único produto em específico, configura-se o que é chama de monopólio natural. As empresas de energia elétrica podem ser também classificadas como representantes de monopólio natural, já que uma de suas peculiaridades que geram esse tipo de monopólio é o fato de que o custo quilowatt-hora de eletricidade cai com o aumento do tamanho da usina, ou seja, da produtividade. Por conseguinte, em razão de serem um monopólio, é preciso que o governo regulamente os preços que as organizações de fornecimento de energia cobram de seus consumidores. Assim, controlando os preços, o governo estimula uma produção de custo baixo, oportunizando que essas organizações obtenham na produção um lucro contábil (MILL, 2017).

Monopsônio: é o mercado configurado por um comprador único, de modo que o preço de venda é determinado por ele. Trata-se de uma situação de concorrência imperfeita, inversa ao monopólio. Um exemplo de mercado monopsônio é uma organização que atua sozinha em uma cidade localizada em um ponto distante, como uma mineradora, onde a oferta de emprego e a atividade econômica do lugar são excessivamente dependentes dessa instituição.

Concorrência perfeita: a principal característica desse tipo de concorrência é a existência de um grande número de fornecedores de um produto exatamente igual, e de compradores informados e desimpedidos para irem atrás da oferta mais atrativa. Assim, existe um preço base que é definido pela relação entre demanda e oferta e que, portanto, não pode ser controlado pelos consumidores e fornecedores. Dessa forma, as organizações precisam lidar com uma infinita e elástica demanda, ou seja, uma curva de demanda que se apresenta na horizontalidade, em paralelo com o eixo das quantidades. $\mathrm{O}$ fornecedor, então, em relação a seus concorrentes, se cobrar um centavo a mais do consumidor, acabará não conseguindo vender seu produto. Por outro lado, se colocar um valor abaixo do valor praticado no mercado, ele sacrificará parte de seu lucro. A venda de arroz e de milho a granel em mercados municipais é um bom exemplo disso. Nesse tipo de mercado, existe um número grande de vendedores de tamanho igual e nenhum deles pode, individualmente, agir sobre o preço de mercado praticado sem ser prejudicado (MOTA, 2009).

Em se tratando dessas estruturas de mercado, é interessante observar também o quadro sistematizado por Marshall: 
Figura 1 - Classificação de Marshall

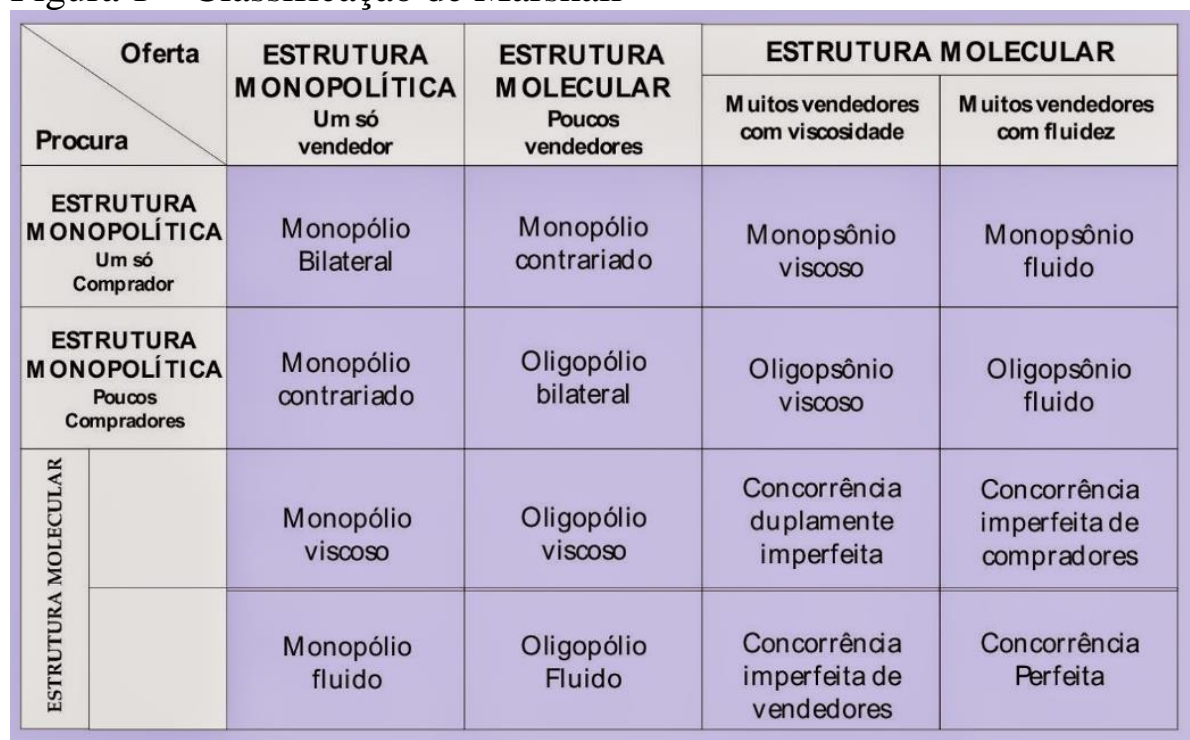

Fonte: Pimenta (2014)

Para as noções conceituais que diferenciam as estruturas de mercado, os elementos de classificação propostos por Marshall são fundamentais. Em suma, o teórico reconhece quatro tipos formais: concorrência monopolística, oligopólios, monopólio e concorrência perfeita. Segundo Pimenta (2014), diferentemente da classificação de Satackelberg, os elementos de diferenciação não se restringem à quantidade de agentes econômicos implicados, abarca também as condições para a ingressão de novas organizações concorrentes no mercado, as possibilidades de concorrência extra preço, a influência que a organização possuí sobre o preço do produto, os produtos comercializados, as propriedades do recurso e ainda fatores comportamentais (PIMENTA, 2014).

A partir dessas considerações a respeito das estruturas de mercado, é preciso considerar o papel da concorrência na sociedade atual. Trata-se de um fenômeno significativo para o desenvolvimento econômico nas diversas áreas e que regula a influência desmedida praticada pelas organizações economicamente dominantes, que concebem corporações monstruosas, mediante mutações empresariais prejudiciais e outras atividades não compatíveis com uma realidade organizada pela concorrência, fator imprescindível para a distribuição de riquezas e para o progresso social e econômico.

Conforme apontam Fonseca e Bosco (2001), teoricamente, os indivíduos são livres para consumir e produzir o que desejarem, uma vez que o mercado é acessível a todos. No entanto, impõe uma regra básica para aqueles que nele escolhem entrar: sobrevivem aqueles que produzem produtos melhores e que conseguirem vender sob as condições mais atrativas para o consumidor.

Dessa forma, a ordem econômica que impera no Brasil legitimou a livre iniciativa como um de seus fundamentos. A iniciativa livre, por sua vez, comporta dois lados: livre concorrência ou liberdade de concorrência, e liberdade de comércio e indústria. A primeira trata do direito de um indivíduo frente a outro, demandando ações eficientes do Estado para constranger ações que possam suprimir a concorrência. A outra expressa o direito do indivíduo frente ao Estado, exigindo a abstenção deste no âmbito da economia (MELO FILHO, 2011).

É em razão da efetiva presença do poder econômico em nossa sociedade que surge a necessidade de se assegurar e de se conservar a livre concorrência. O próprio texto constitucional reconhece sua existência. Contudo, a eliminação total do poder econômico pode ser nociva, como a sua não existência também pode inviabilizar grandes investimentos e a realização de obras importantes para o desenvolvimento social e econômico (MELO FILHO, 2011).

Ainda assim, tal ideal libertário foi paulatinamente sendo prejudicado por questões econômicas e técnicas, responsáveis por atrapalhar a mobilidade social e a livre concorrência, 
necessárias para o pleno funcionamento do sistema econômico, resultando na formação de cartéis e oligopólios e em uma crescente estratificação social (SALLES, 1996).

Ademais, conforme salienta Toigo (2010), no que diz respeito a concentração empresarial, existe um paradoxo: por um lado ela é nociva para a economia, deixando o sistema instável e, por conseguinte, promovendo a dominação de mercado, a multiplicação arbitrária dos lucros e a eliminação da concorrência; por outro, ela é favorável à eficiência do sistema de produção e ao progresso social e econômico. Por assim dizer, é necessário manter atenção e cautela para que a concorrência não seja eliminada e para que a dominação de mercado não ocorra, pois que, do contrário, o prejudicado é o consumidor, isto é, a população em sua maioria. No Brasil, Isso não só infringe a Lei antitruste, como confronta os princípios básicos constitucionais.

Em um mercado ideal, a "concorrência perfeita" seria responsável por promover a igualdade entre todos os agentes econômicos. Nesse tipo de concorrência, há inúmeros fornecedores e nenhum deles se sobressai em grandiosidade e em poder econômico a ponto de conseguir influenciar significativamente o preço dos produtos e, consequentemente, o mercado em sua totalidade. No lado oposto, o do comprador, haveria grande quantidade de consumidores esclarecidos e instruídos sobre como o mercado funciona e capazes de buscarem as melhores ofertas. Teoricamente, funcionaria semelhantemente a uma feira livre, em que muitos indivíduos comercializam suas mercadorias de forma transparente e sob a mesma condição (GLÓRIA, 2003).

Por outro lado, conforme esclarecem Samuelson e Nordhaus (2012), a partir de analises dos fatores que determinam a concentração em uma concorrência imperfeita, constatou-se que nesse tipo de estrutura de mercado atuam três fatores básicos: a interação estratégica, as barreiras à entrada de outros concorrentes e as economias de escala (estes dois últimos já foram tratados no capítulo anterior, portanto, na próxima sessão, será abordada de forma mais detalhada a interação estratégica).

Segundo Francischini (2013), o estudo da concorrência está associado aos fatores econômicos ligados à falta de recursos e à escassez de produtos concorrentes, à relação entre custos de produção e de distribuição, da estabilidade do mercado e da sua elasticidade. Quer dizer, está ligada a questões mercadológicas, que visam coibir que não ocorram ações excessivas ou abusivas.

Assim sendo, somente se for usado abusivamente é que o poder econômico se torna um problema. O uso imoderado desse poder resulta na multiplicação arbitrária dos lucros, na supressão da concorrência ou na dominação dos mercados. Ainda que o livre comércio seja um direito social, o indivíduo não está autorizado a, por intermédio de seu exercício, prejudicar interesses sociais ou outros indivíduos. Dessa forma, enquanto um tipo de proteção do sistema concorrencial mercadológico, a liberdade de concorrência é substancial, já que tem como função impedir ou dificultar a utilização indevida do poder econômico (MELHO FILHO, 2011).

Enquanto uma área de estudo e de regulamentação do mercado em sua completude, abrangendo consumidor, Estado e a empresa, o Direito Econômico é para o Estado um instrumento de intervenção no âmbito econômico.

A respeito disso, Leopoldino (2001, p. 179) diz o seguinte:***

[...] o fenômeno da concentração do poder econômico nas mãos de uns poucos veio trazer a necessidade de o Estado intervir para sanar a crise do liberalismo econômico, salvando a liberdade de iniciativa. Assinale-se que o Estado não interveio para coibir a liberdade econômica das empresas, mas para garanti-la mais concreta e efetivamente.

Portanto, são raras as ocasiões em que o Estado age diretamente sobre a atividade econômica, pois que a prescrição é a de que o Estado deve evitar esse tipo de ação. Contudo, são 
duas as condições em que isso ocorre: quando há significativo interesse da população ${ }^{1}$ ou quando a segurança nacional está em jogo.

Seguindo nessa linha de raciocínio, o Estado deve se colocar do lado de fora do mercado, mas mantê-lo sob constante observação, atuando sobre ele apenas como agente regulador (mantendo a economia equilibrada) e normativo. A partir do momento em que seu poder de interferir na economia foi reduzido, o Estado passou a assumir as funções de fiscalizar, planejar e incentivar, de modo que, com isso, a defesa da concorrência voltou a receber destaque no contexto econômico do Brasil (MIRANDA, 2015).

O acirramento da concorrência, a busca por novos mercados, a estandardização dos produtos e, sobretudo, o comportamento parasitário e emulatório de determinados agentes econômicos, de fato, ocasionam certas ações, imorais e incoerentes com a lei, que se espalham pelo âmbito do direto de concorrência, exigindo, assim, uma adequada resposta por parte de juristas (BITTAR, 1989).

O desejo de qualquer empresa é, fundamentalmente, aumentar seu número de clientes em detrimento das empresas concorrentes. Tal objetivo, para ser alcançado, inspira a utilização de meios inidôneos, de modo a transgredir as regras do jogo e perturbar o equilíbrio do livre mercado, gerando danos para os verdadeiros titulares dos direitos infringidos, aqueles que sabem discernir a falta de lealdade competitiva de uma postura idônea (OLIVEIRA, 2009).

Na história brasileira, os primeiros passos em sentido ao combate do uso abusivo do poder econômico foram motivados pelo aumento arbitrário dos preços, assim como ocorreu na Inglaterra. No Estado Novo, foram publicados dois decretos com o objetivo de coibir ações abusivas e fusões e associações entre empresas que tornassem a concorrência injusta, os quais são: decreto $\mathrm{n}^{\circ}{ }^{\circ}$ 869/1938 e, em seguida, o decreto n. 4.407/1942, que tomou o lugar do primeiro. Conforme os ideais da época, que desprestigiavam os valores do Estado de Direito, os decretos determinavam pena de prisão, sem direito a julgamento pelo Tribunal de Segurança ou direito à liberdade condicional. No entanto, assim que Getúlio Vargas foi destituído, o decreto de 1942 foi revogado.

As preocupações quanto ao emprego abusivo do poder econômico não desapareceram, de forma que, no texto constitucional de 1946, incluiu-se um dispositivo com o intuito de coibir esse tipo de ação. Por muito tempo o projeto de lei que regulamentou o dispositivo constitucional permaneceu retido no Congresso, sendo editado apenas em 1962, com a Lei n. ${ }^{\circ}$ 4.137, que estabeleceu o primeiro antitruste legal e criou um órgão para garantir seu cumprimento, o Conselho Administrativo de Defesa Econômica (CADE). Trata-se de autarquia, incumbida de investigar e julgar casos que envolvam acordos entre concorrentes que causem danos à livre concorrência, preços predatórios, vendas casadas e etc. (MOTTA, 2015).

É preciso ressaltar ainda que, em se tratando do ordenamento jurídico brasileiro, a Constituição Federal de 1988 regulamenta como os agentes econômicos devem atuar, erigindo como valores sociais do trabalho e da livre iniciativa no art. $1^{\circ}$, IV, e, mais adiante, a livre concorrência, no art. 170, IV. Além disso, dispõe sobre os direitos autorais e industriais e, no art. $173, \S 4^{\circ}$, prevê a punição de excessos por parte do poder econômico, ou seja, de ações que objetivam a multiplicação arbitrária dos lucros, a supressão da concorrência e a dominação abusiva dos mercados.

Assim sendo, a livre concorrência surge como um direito constitucionalmente previsto e se impõe como fundamento básico para qualquer atividade mercadológica. Os princípios presentes no art. 170 da CF/88, dentre os quais está a livre concorrência, não se coadunam com o exercício de atividades econômicas que visem unicamente o lucro, desconectado de uma função social.

Segundo Nascimento Neto (2009), o texto constitucional impõe limites e determina objetivos para o desempenho da atividade econômica, como dever ser praticada, sempre, de forma

\footnotetext{
${ }^{1}$ Dispõe o artigo 173 da CF/88: "Ressalvados os casos previstos nesta Constituição, a exploração direta da atividade econômica só será permitida quando necessária aos imperativos da segurança nacional ou a relevante interesse coletivo, conforme definidos em lei”
} 
a promover a justiça social, preservar a dignidade da pessoa humana, e ser norteada pelo cumprimento dos princípios constitucionais, tal qual a livre concorrência.

A livre concorrência, portanto, resulta da livre iniciativa, sendo sua garantia. Isto é, caso a livre concorrência não ocorra afetivamente, em consequência, a livre iniciativa se torna impossível. Por conseguinte, faz-se necessário definir conceitualmente o que é a livre iniciativa (NASCIMENTO NETO, 2009).

NCIDENTE DE INCONSTITUCIONALIDADE - LEI MUNICIPAL VEDAÇÃO DE COMÉRCIO ATACADISTA DE HORTIFRUTIGRANJEIROS FORA DAS INSTALAÇÕES DO CEASA-PR - AFRONTA AOS PRINCÍPIOS DA LIBERDADE DE EXERCÍCIO DE ATIVIDADE ECONÔMICA E LIVRE CONCORRÊNCIA - INTELIGÊNCIA DO ART. 170, INCISO IV , E ART. $173, \S 4^{\circ}$, AMBOS DA CONSTITUIÇÃO FEDERAL LEI MUNICIPAL 4.226 /96 DE MARINGÁ DECLARADA INCONSTITUCIONAL - INCIDENTE PROCEDENTE. "A ordem econômica, fundada na valorização do trabalho humano e na livre iniciativa, tem por fim assegurar a todos existência digna, conforme os ditames da justiça social, observados os seguintes princípios: IV - livre concorrência;" (art. 170 , IV , da Constituição Federal )."A lei reprimirá o abuso de poder econômico que vise à dominação dos mercados, à eliminação da concorrência e ao aumento arbitrário dos lucros." (art. 173, § $4^{\circ}$, da Magna Carta). A lei municipal que veda o funcionamento de comércio atacadista de hortifrutigranjeiros fora das instalações do CEASA-PR afronta os princípios da liberdade de exercício de atividade econômica e da livre concorrência, reclamando, por consequência, a declaração de sua flagrante inconstitucionalidade. (TJ-PR - Incidente de Declaração de Inconstitucionalidade: 617537501 PR 0617537-5/01)

Vale ainda dizer que, no Brasil, o suporte legal da regulamentação do Direito de Concorrência, até novembro de 2011, era a Lei n. ${ }^{\circ}$ 8.884/1994. Hoje em dia, o Sistema Brasileiro de Defesa da Concorrência é sustentado pela Lei n. ${ }^{\circ} 12.529 / 2011$, responsável por prevenir e reprimir infrações cometidas contra a ordem econômica do país.

Por assim dizer, a lei combate a formação de monopólios econômicos que resultem da supressão de empresas concorrentes do mercado que, por sua vez, possa ter sido conseguida por meios ilícitos. Além disso, coíbe monopólio de mercado que, mesmo tendo sido obtido de forma licita, possa, possivelmente, determinar quantidades e preços caso o direito à liberdade venha a ser praticado de forma abusiva (ARAÚJO; FORTES, 2009).

De acordo com Leal (2012), modificações estruturais no Sistema Brasileiro de Defesa da Concorrência (SBDC), integrado pelos órgãos incumbidos de garantir a efetividade das normas de Defesa da Concorrência, foram introduzidas pela Lei n. ${ }^{\circ}$ 12.529/2011, alterando tanto a investigação de condutas anticompetitivas como a análise de ações de concentração. Essas mudanças objetivaram, em especial, reduzir problemas ligados à burocracia e à lentidão dos processos, à notificação das ações de concentração com resultados pouco significativos para o domínio econômico e à análise desenvolvida por mais de uma instituição.

Fatos específicos de concorrência desleal são legislativamente tratados pela Lei de Propriedade Industrial (LPI, Lei n. ${ }^{\circ}$ 9.279/96), que, em seu art. 195, tem definido o delito de concorrência desleal, sendo referenciada em leis como a de Antitruste (Lei n. ${ }^{\circ}$ 8.884/94), que classifica, no art. 21, VII, como concorrência desleal a exigência de exclusividade para propaganda publicitária.

Assegurado pelo Código Civil (art. 927), o prejudicado tem direito ao ressarcimento por danos causadas por concorrência desleal, quer dizer, por ações que depreciem sua reputação ou seus negócios. 
Além disso, em se tratando da promoção do bem-estar social, as implicações da concorrência dinâmica em si se demonstram sempre favoráveis. A tecnologia, por facultar certo poder econômico às empresas que dela fazem uso, vem a ser algo buscado por todas as organizações, resultando em uma concorrência que visa sempre o melhoramento dos processos produtivos. Tal concorrência, denominada dinâmica, é diretamente responsável pela redução de custos e pelo aprimoramento dos produtos vendidos no mercado (ARAÚJO; FORTES, 2009).

Assim, reunindo uma séria de dispositivos legais, institucionais e regulamentares que buscam assegurar a observância do princípio constitucional da livre iniciativa, cabe ao direito concorrencial disciplinar todas as práticas econômicas de mercado, equilibrando o jogo de forças que se instaura entre demanda e oferta de bens e serviços.

Conforme Salomi (2012), esse campo do direito é constituído por uma soma de normas jurídicas reservadas à investigação, coibição e prevenção das diversas formas de excesso de poder econômico, com o objetivo de inibir a formação de monopólios de mercado e, em prol da população em geral, contribuir para o exercício da livre iniciativa.

Essa divisão do direito empresarial, segundo Carvalho (2012), busca fixar limites para atividades mercadológicas que possam perturbar, de alguma forma, a livre concorrência, como o emprego, pelas grandes corporações, principalmente, do poder econômico desmedido, e práticas anticoncorrenciais que possam frustrar o desenvolvimento e/ou o crescimento de empresas em benefício de outras, mais fortes e maiores.

Tais ações negativas lesionam o direito de livre concorrência de diferentes formas, cujos reflexos são: falta de preço justo, refreamento do progresso tecnológico, problemas quanto à geração de vagas empregatícias etc.

O Sistema Brasileiro de Defesa da Concorrência (SBDC) é composto pela Secretaria de Acompanhamento Econômico do Ministério da Fazendo e pelo Conselho Administrativo de Defesa Econômica (CADE), tendo suas incumbências legalmente previstas.

Sendo uma autarquia federal vinculada ao Ministério da Justiça, com foro e sede em Brasília (DF), o CADE tem como função velar pela livre concorrência e pelo bom funcionamento do mercado. Por conseguinte, enquanto entidade da esfera do Poder Executivo, a autarquia é responsável tanto por fomentar e difundir a cultura de livre concorrência quanto por investigar e deliberar, em instância final administrativa a respeito dessa matéria (FRANCISCHINI, 2013).

O papel de entidade repressora é desempenhado pelo CADE conforme a Lei n. ${ }^{\circ}$ 12.529/11, art. 36, que define atos infracionais perante o sistema econômico de mercado.

Art. 36. Constituem infração da ordem econômica, independentemente de culpa, os atos sob qualquer forma manifestados, que tenham por objeto ou possam produzir os seguintes efeitos, ainda que não sejam alcançados:

I - limitar, falsear ou de qualquer forma prejudicar a livre concorrência ou a livre iniciativa;

II - dominar mercado relevante de bens ou serviços;

III - aumentar arbitrariamente os lucros; e

IV - exercer de forma abusiva posição dominante.

(...)

Percebe-se que o artigo supracitado elenca apenas alguns de atos que configurariam ilicitude, podendo aí ser incluso ainda outros mais que contrariem o interesse do comprador e prejudiquem a ordem econômica.

Em se tratando do percurso histórico do CADE no Brasil, de acordo com Motta (2014), entre os anos de 1963 e 1990, período que marca sua fase inicial, a entidade se encarregou de 337 processos, dentre os quais 117 foram instaurados, resultando em 16 condenações, todas elas reconsideradas pelos Tribunais responsáveis. Como se pode perceber, o CADE foi ineficaz nesses primeiros anos, espelhando, assim, a falta de conciliação entre as funções do órgão e uma economia 
de mercado, em um contexto marcado por sucessões governamentais e por recorrentes intervenções estatais sobre as questões econômicas de preço, investimento e produção. Após isso, governos militares mantiveram o controle sobre a economia por mais de vinte anos, tempo esse em que não existia espaço para a laboração legítima de uma entidade com as incumbências do CADE. O controle econômico era realizado pelo Estado mediante o estímulo de acordos entre concorrentes e de concentrações, especialmente por meio do controle de preços, que determinava reajustes setoriais e que, consequente, impossibilitava a livre concorrência.

Atualmente, o CADE é responsável por inibir formações de monopólios, cartéis e a concentração econômica, de modo a evitar danos à concorrência, já verificados antes, em prol do correto funcionamento do sistema econômico de mercado. Em países desenvolvidos, onde o sistema concorrencial é melhor estruturado e regulado, órgãos como a Comissão Europeia, na União Europeia, e a Federal Trade Commission, nos EUA, já vêm acolhendo há muito tempo, e solucionando por meio de medidas efetivas, casos semelhantes aos que o CADE, nos últimos tempos, tem investigado e tem buscado resolver da melhor forma possível, como a compra da Pains pela Gerdau, ou a compra Kolynos pela Colgate, ou a união da cervejaria Brahma com a Antarctica, entre outros.

Por outro lado, recorrer ao Poder Judiciário é a única alternativa disponível para a organização que entenda ter sido lesada por alguma das medidas tomadas pelo CADE, que constitui um importante dispositivo de regulação econômica, por meio do qual se pode monitorar atos ilícitos e garantir a livre concorrência de mercado. Com efeito, alinha-se o princípio constitucional de livre concorrência com as práticas econômicas operadas no mercado brasileiro, de modo a oferecer ao comprador produtos de qualidade e opções de preço, assim como oportunizando ao empreendedor, mesmo que com uma empresa de porte pequeno, ou mesmo com uma microempresa, a entrada e atuação no mercado nacional.

Conclui-se, portanto, que a livre concorrência é, enquanto princípios constitucionais, representa importantíssimo instrumento de garantia do bem-estar social. Possui plena aplicação sobre a economia e destina-se a agentes públicos e privados, pois que, se por um lado, as ações do Estado em prol da concorrência objetivam prevenir e inibir prejuízos ao sistema econômico e, dessa forma, preservar a livre concorrência, por outro lado, o livre desempenho das atividades econômicas privadas garante a natural regulação da concorrência de mercado.

\section{REGULAÇÃO E CONCORRÊNCIA NOTARIAL}

Explanou-se, no início desse breve artigo, sobre a concorrência nos seus aspectos ligados à teoria econômica. A partir daí, chegou-se ao modelo concorrencial abraçado pela Constituição Federal, no qual o binômio constituído pelo objetivo de construir uma sociedade justa, livre e solidária, fundamentada na dignidade da pessoa humana (art. $3^{\circ}, \mathrm{I} \mathrm{e}^{\circ}{ }^{\circ}$, III, CF, respectivamente), conjuga-se necessariamente com a busca de garantir o desenvolvimento nacional, tendo como sustentáculo os valores sociais do trabalho e da livre iniciativa como valores sociais (art. $3^{\circ}$, III e $1^{\circ}, \mathrm{IV}, \mathrm{CF}$, respectivamente). Esta exegese resulta na consagração da de uma ordem econômica fundada na valorização do trabalho humano e da livre iniciativa, a qual tem como um dos seus princípios a livre concorrência como seu desdobramento lógico. Nas próximas linhas, tentaremos mostrar como a concorrência na atividade notarial se situa dentro dos parâmetros teóricoeconômicos acima traçados, e como é possível o exercício da concorrência entre os tabeliães de notas dentro das rígidas limitações estabelecidas pelo arcabouço jurídico que cerca atividade.

\subsection{Regulação notarial, classificação e sistema concorrencial do notariado brasileiro}

Poucos estudiosos dão a devida atenção às serventias extrajudiciais previstas no artigo 236, da Constituição Federal. Conhecidas popularmente pela expressão "cartório", esses serviços, 
públicos na sua essência, tem sua execução delegada a particulares, selecionados em concurso de público de provas e títulos, assim determinado pelo constituinte originário, Na forma do art. 236, parágrafo 3, da Lei Maior. (BRASIL, 1988)

Ferreira e Rodrigues (2016, p. 30), compilam os princípios institucionais da atividade, fixados na Constituição Federal, os quais norteiam sua regulação e fiscalização, a saber:

- $\quad$ exercício em caráter privado, mediante delegação outorgada pelo Estado;

- regulação da atividade e a responsabilidade civil e criminal de notários e seus prepostos estabelecidas por lei federal;

- $\quad$ fiscalização a cabo do Poder Judiciário;

- $\quad$ cobrança de emolumentos com normas gerais previstas em lei federal; ingresso na atividade por concurso público de provas e títulos.

Com efeito, as transformações introduzidas pela Constituição de 1988 no regime jurídico notarial e registral foram profundas. $\mathrm{O}$ que antes era "caracterizado como "simples serventia do Poder Judiciário", tornou-se um serviço público privatizado, ou, em outras palavras, "um serviço público "exercido em caráter privado"”, conforme doutrina Silva (2.000), referindo especificamente ao notariado, mas cujos os ensinamentos podem ser aplicados igualmente à atividade registral.

Nesse sentido, o artigo $1^{\circ}$, da Lei $8.935 / 94$, o qual regulamentou o $\S 1^{\circ}$, da Lei Maior, estabelece que "serviços notariais e de registro são os de organização técnica e administrativa destinados a garantir a publicidade, autenticidade, segurança e eficácia dos atos jurídicos" (BRASIL, 1994).

Para podermos classificar a concorrência existente na atividade notarial é preciso entender, primeiro, o que é um tabelião de notas e a qual tipo de notariado estamos nos referindo.

É a própria lei que define o tabelião e o oficial de registro. A Lei 8.935/94 (BRASIL, 1994), considerada o diploma legal de regência da atividade, em seu artigo 3o, define o tabelião (ou notário), assim como o oficial de registro (ou registrador), como "profissionais do direito, dotados de fé pública, a quem é delegado o exercício da atividade notarial e de registro" (BRASIL, 1994).

Tal delegação é outorgada por concurso público de provas e títulos, conforme determina o parágrafo 3o, do artigo 236, da Constituição Federal. No plano infraconstitucional, os artigos 14 a 19 da Lei 8.935/94 (BRASIL, 1994) esmiúçam a forma de acesso à atividade, complementados pela Resolução 81/2009, do Conselho Nacional de Justiça, e pelas leis e normas estaduais que não conflitem com o regramento federal (BRASIL, 2009).

Nosso notariado é do tipo latino (BRANDELLI, 2007, p. 121; FERREIRA; RODRIGUES, 2016, p. 28). O adjetivo "latino" não se refere aos países latinos, mas sim "às instituições jurídicas oriundas do Direito Romano", conforme esclarecem Ferreira e Rodrigues. Na mesma senda, Brandelli (2007), quando afirma que "notariado latino" é o nome que se dá ao notariado dos países "que seguem o direito herdado dos romanos". O notariado latino está presente em 86 países do mundo (FERREIRA; RODRIGUES, 2016, p. 28), sendo 39 só na Europa, dos quais podemos citar Alemanha, Áustria, Bélgica e Países Baixos, entre outros. Acrescente-se que esse tipo de notariado foi o adotado pela maioria dos países do antigo bloco comunista, após a queda do Muro de Berlim, tais como Rússia, Romênia, República Tcheca, Polônia, Croácia, Armênia, dentre vários outros.

Adriana Arbella (apud BRANDELLI, 2007, p. 121), sintetiza o notário latino como sendo:

"Um profissional do direito encarregado de uma função pública, que consiste em receber, interpretar e dar forma legal à vontade das partes, redigindo os documentos adequados a esse fim, conferindo-lhes autenticidade, conservando os originais destes e expedindo cópias que dão fé de seu conteúdo". 
Para análise do sistema concorrencial na atividade notarial, quatro características pertinentes ao notariado latino devem ser destacadas, a saber:

1- Os utentes do serviço são livres para escolher o tabelião de sua preferência para lavratura dos atos de seu interesse, independentemente do local de seus domicílios, ou de onde se situa o bem objeto da escritura (BRASIL, 1994, art. $8^{\circ}$ );

2- Os notários não podem lavrar atos fora da base geográfica para qual lhes foi outorgada a delegação (BRASIL, 1994, art. $9^{\circ}$ );

3- Limitação do número de notários às necessidades locais onde funcionam. Nesse sentido, foi determinado por unanimidade, na $168^{a}$ Sessão Ordinária do Conselho Nacional de Justiça (CNJ). Da mesma forma decidiu o Supremo Tribunal Federal por unanimidade, em 29/06/2011, na ADI 4140, formulada pela Associação dos Notários e Registradores do Brasil (Anoreg) contra atos normativos do Tribunal de Justiça do Estado de Goiás que tratam da reorganização de serviços e da realização de concursos para cartórios, que "serviços notariais e de registro devem ser criados ou reestruturados por meio de lei formal de iniciativa do Poder Judiciário" (BRASIL, 2011, p. 1).

4- Remuneração dos atos praticados de acordo com tabelas de emolumentos determinadas por lei (Lei 8.935/94, art. 30, VII, VIII e IX). É pacífica a jurisprudência do STF no sentido que os emolumentos possuem natureza tributária na modalidade de taxa. Destarte, cobrança a maior pelo notário significa excesso de exação. Cobrança a menor é isenção sem previsão legal.

Isso posto, em conformidade com o anteriormente exposto, temos a seguinte estrutura de mercado presente na atuação notarial.

Em comarcas onde apenas onde há apenas um tabelião, temos uma situação de monopólio com características próprias, pois, muito embora nessa comarca apenas um notário possa lavrar os atos de sua competência, ele não possui o poder de impor à sua clientela os valores que bem entender. Ou seja, tal fato não lhe permite tirar vantagem econômica sobre os preços de seus serviços, como normalmente ocorre nos mercados monopolizados. Isso vale também para comarcas maiores, onde haja dois ou mais tabeliães atuando. Nessa situação, podemos afirmar que reina uma realidade de oligopólio, onde vários tabeliães disputam entre si a clientela, mas com as mesmas restrições em relação às comarcas onde atua somente um profissional.

Ressalve-se, como mencionado acima, que os tabeliães possuem competência para lavrar atos somente no município para o qual receberam a delegação (art. $9^{\circ}$, da Lei 8.935/94). Na prática, não impera uma aplicação literal desse dispositivo, tanto é assim que, no Estado de São Paulo, a delegação é outorgada para determinada comarca, a qual, muitas vezes, é formada por mais de um município. De toda sorte, seja em município ou em comarca, sempre haverá uma delimitação clara quanto à área territorial para a qual o tabelião tem competência para atuar. Embora contem sempre a seu favor com uma estrutura de mercado monopolizada ou oligopolizada, isso tem seu contraponto na limitação territorial a que está submetido o tabelião. Destarte, caso queira, o usuário sempre poderá lavrar seu ato com um tabelião diverso do local onde more ou de onde esteja situado o bem.

Isso nos leva a indagar sobre o grau de concorrência existente na atividade notarial. A despeito de trabalharem com um produto homogêneo, pelo menos em tese, não há como negar que há diferenças entre os serviços prestados pelos tabeliães. Preparo acadêmico, correta interpretação da problemática jurídica apresentada pelo usuário, escrituras redigidas com apuro técnico e clareza, ao lado de instalações confortáveis e de fácil acesso, entre outros fatores, diferenciam um tabelião do outro e permitem a criação de um satisfatório ambiente concorrencial entre eles. Não se trata, é 
claro, de uma concorrência perfeita, pois como dito, nosso notariado é de número certo, o qual somente pode variar por força de lei. Igualmente não vige no tabelionato o sistema de livre iniciativa, uma vez que eles exercem atividade jurídica e, muito embora a façam com finalidade lucrativa, isso não é o suficiente para caracterizá-la como uma atividade empresarial. Ou seja, não se pode "abrir" um cartório de notas como se abre uma loja de roupas, um hotel ou um restaurante. É preciso que uma serventia fique vaga, dentre as hipóteses de vacância previstas em lei, seja aberto um concurso público para preenchê-la e, ao final, outorgar a delegação ao aprovado, observandose a rigorosa ordem de classificação do certame. Destarte, não podem ser consideradas inconstitucionais as restrições impostas à atividade, pois elas não são afrontosas aos princípios constitucionais da livre iniciativa e da livre concorrência.

A publicidade é extremamente regrada. Nesse sentido, assim dispõe as Normas de Serviço da Corregedoria da Justiça do Estado de São Paulo, no seu Capítulo XIV, item 3.1:

A competição entre os Tabeliães de Notas deve ser leal, pautada pelo reconhecimento de seu preparo e de sua capacidade profissional e praticada de forma a não comprometer a dignidade e o prestígio das funções exercidas e das instituições notariais e de registro, sem utilização de publicidade individual, de estratégias mercadológicas de captação de clientela e da intermediação dos serviços e livre de expedientes próprios de uma economia de mercado, como, por exemplo, a redução de emolumentos.

Ressalve-se que tais restrições não tem previsão legal, nem constitucional. Mas por força do artigo 29, XIV, da Lei 8.935/94, é dever do tabelião "observar as normas técnicas estabelecidas pelo juízo competente" (BRASIL, 1994). Tem havido tolerância com as novas mídias eletrônicas, tais como páginas de tabelionatos, postadas nas redes sociais, e sítios de cartórios hospedados na rede mundial de computadores, os quais contém mensagens com o claro intuito de atração de clientela.

Tais iniciativas não devem ser coibidas, desde que não consubstanciem uma explícita estratégia mercadológica. A liberdade lato sensu é um direito fundamental mencionado 27 vezes Constituição Federal, desde o preâmbulo, passando pelo caput do art. $5^{\circ}$, assim como no artigo 170, que trata da Ordem Econômica. Por sua vez, a palavra "livre" vem estampada 28 vezes na lei Maior, merecendo menção a consagração do valor da livre iniciativa, no artigo $1^{\circ}$, inc. IV, e a construção de uma sociedade livre como objetivo fundamental da República, no artigo $3^{\circ}$, inc. I. Não por acaso, portanto, a consagração do princípio da livre escolha do tabelião pelo art. $8^{\circ}$, da Lei 8935/94, como direito do usuário dos serviços notariais, a escolha quanto ao tabelião que irá lavrar seu ato, independente do local em que se situa o objeto da escritura. Mas importante destacar que esse direito só poderá ser exercido plenamente, revestindo-se de concretude e materialidade, caso haja informação a respeito dos tabelionatos e dos serviços que oferecem. Do contrário, tal direito resultaria em letra morta, existindo apenas sob o aspecto formal.

\section{EXERCÍCIO DA CONCORRÊNCIA NOTARIAL}

Muito embora haja enormes restrições para que a concorrência notarial possa ser exercida - a normativa administrativa paulista utiliza a palavra competição -, é possível ao tabelião se destacar dos demais e atrair clientela para sua serventia dentro das regras existentes, sem praticar nenhuma ilicitude, tais como publicidade individual, utilização de intermediários para captação de serviços ou redução de emolumentos, prática usual entre os maus tabeliães.

Os serviços notariais devem ser oferecidos dentro de um padrão mínimo de qualidade, estabelecidos na lei de regência e na normativa infra legal.

A lei 8.935/94 assim estabelece: 
Lei 8935/94, art. $4^{\circ}$ : Os serviços notariais e de registro serão prestados, de modo eficiente e adequado, em dias e horários estabelecidos pelo juízo competente, atendidas as peculiaridades locais, em local de fácil acesso ao público e que ofereça segurança para o arquivamento de livros e documentos.

Por seu turno, as Normas de Serviço da Corregedoria da Justiça do estado de São Paulo (NSCGJSP) estabelecem no seu capítulo XIV, item 20

20. Os notários e registradores disponibilizarão a adequada e eficiente prestação do serviço público notarial ou de registro, mantendo instalações, equipamentos, meios e procedimentos de trabalho dimensionados ao bom atendimento, bem como número suficiente de prepostos.

Nesse sentido, há um padrão mínimo de qualidade estabelecido no regramento da atividade a ser observado pelos respetivos titulares na prestação dos serviços. E é justamente no oferecimento de um padrão de qualidade que vai além desse mínimo que constitui o campo lícito no qual a concorrência notarial, de forma reflexa, pode ser travada. Em outros termos, sendo os serviços exercidos em caráter privado, dada a sua natureza pública, existe forte regulação no que toca a competição entre serventias, é justamente na busca da melhor excelência na prestação de tais serviços, ao lado de algumas outras iniciativas, o caminho para ampliação e manutenção da base de clientes do tabelionato.

Ressalve-se que, com o advento da Lei 13.286/2016, a qual deu nova redação ao artigo 22, da Lei 8935/94, a responsabilidade civil do notário (e do registrador) passou a exigir o elemento culpa para sua materialização, prescrevendo em três anos a pretensão de reparação, na forma do seu $\S$ único, já com a nova redação ${ }^{2}$. Tirante esse fato, o risco econômico pelo exercício da delegação não sofreu nenhuma alteração, sendo inteiramente do titular.

$\mathrm{Na}$ linha do que foi acima exposto, podem-se catalogar as seguintes iniciativas a serem executadas:

a) Localização da serventia. Essa talvez seja a mais importante variável a ser trabalhada pelo tabelião de notas. Atendidos os padrões mínimos de acessibilidade, conforto e higiene exigidos pela corregedoria local, é o tabelião quem determina o local de sede do cartório. A ele caberá escolher se a serventia ocupará um imóvel de frente para a avenida mais movimentada da cidade, com grande visibilidade pública, de modo a tornar o cartório conhecido de todos. Ou se, ao contrário, as instalações ficarão nesse mesmo quarteirão, mas serão acanhadas, escondidas em uma rua lateral. Como há vedação para veiculação de publicidade ordinária, é vital encontrar maneiras de se tornar conhecido para os clientes em potencial e, para tanto, a localização do cartório é decisiva. Portanto, faça da sede da serventia o seu próprio outdoor.

b) Estrutura física e humana. Um bom serviço demanda investimento em estrutura, seja ela física ou humana. É preciso ter funcionários bem treinados, capacitados e em bom número. Cliente detesta perder tempo, especialmente em fila ou em atendimento displicente e demorado. Os funcionários precisam ter foco no cliente, nas suas necessidades, e atendê-los com cortesia e preparo técnico. A estrutura física deve oferecer mobiliário novo e confortável, máquinas e equipamentos modernos, banheiros limpos e estacionamento amplo, dentre outros itens importantes para prestação de um serviço seguro e eficiente, que ao mesmo tempo faça o cliente se sentir bem atendido e confortável.

\footnotetext{
${ }^{2}$ Em fevereiro de 2019, o Plenário do Supremo Tribunal Federal (STF) reafirmou jurisprudência da Corte segundo a qual o Estado tem responsabilidade civil objetiva para reparar danos causados a terceiros por tabeliães e oficiais de registro no exercício de suas funções cartoriais. Por maioria de votos, o colegiado negou provimento ao Recurso Extraordinário $\mathrm{n}^{\circ}$ 842.846, com repercussão geral reconhecida, e assentou ainda que o Estado deve ajuizar ação de regresso contra o responsável pelo dano, nos casos de dolo ou culpa, sob pena de improbidade administrativa.
}

Revista de Direito Brasileira | Florianópolis, SC | v. 24 | n. 9 | p.274-292 | Set./Dez. 2019 
c) Fazer parcerias. Não se está a falar de parcerias formais, com perfil comercial, o que é vedado pelas normativas administrativas locais. Isso precisa ficar claro. A parceria aqui tratada refere-se a uma cooperação natural e de alto nível, derivada do relacionamento existente com públicos alvos específicos e determinados, os quais constituem usuários dos serviços notariais por força de imposições legais, tais como advogados, corretores de imóveis, vendedores de automóveis, empresas que participam de licitações públicas, entre outros profissionais ou instituições. Torne-os mensalistas do cartório, conheça-os pelo nome e dê a eles o atendimento mais personalizado e adequado possível às suas necessidades. Não se está recomendando qualquer discriminação entre os usuários de grande volume de serviços notariais dos demais usuários, o que seria ilegal e inconstitucional, mormente face á natureza pública da atividade. O que se está recomendando é a observância do princípio da eficiência, previsto no artigo 37, da Constituição Federal. Logo, pessoas e empresas que, por força de lei, demandam serviços dos tabelionatos de notas em grande escala precisam contar com uma prestação dos serviços dentro de um nível de profissionalismo e eficiência compatível com suas necessidades. Na medida em que o atendimento diferenciado desses públicos em nada prejudique o serviço prestado ao restante da clientela, e todos, indistintamente, possam ter acesso às mesmas diferenciações, caso necessitem, nada há de irregular nisso.

d) Aparecer na mídia 1. A atividade tabeliã deve ser notícia na imprensa. A toda hora novos serviços estão sendo oferecidos pelos cartórios: inventários, apostilamento de documentos para uso no exterior, mediação e conciliação, atendimento de deficientes auditivos pela Linguagem Brasileira de Sinais (LIBRAS), lavratura de cartas de sentença, e muito mais. Essas inovações são fatos revestidos de interesse público, cuja divulgação é necessária também para os meios de comunicação. Afinal, eles têm que preencher todos os dias seus jornais e telejornais com uma pauta de notícias úteis ao leitor e ao telespectador.

e) Aparecer na mídia 2. È impossível para os profissionais de imprensa estarem atentos a tudo o que acontece. Muitas vezes, é importante contatá-los para chamar a atenção sobre algum assunto do momento, sugerir um artigo ou dar uma entrevista. Faça do jornalista um amigo. Ele precisa a todo o momento ouvir especialistas ao escrever matérias de conteúdo mais específico, tanto quanto o especialista precisa aparecer na mídia para se tornar conhecido.

f) Aparecer na mídia 3: Está-se falando de internet. Crie uma página nas redes sociais. Faça um sítio do seu cartório. Grave vídeos com comentários jurídicos sobre assuntos do momento, ligados à atividade notarial, e divulgue-os nas redes sociais.

g) Interagir com a sociedade. É importante participar de eventos, fazer cursos, dar palestras, escrever livros e artigos científicos. É fundamental interagir com a sociedade e não ficar enclausurado dentro da sede da serventia. Isso torna o tabelião um profissional conhecido e aumenta a sua respeitabilidade perante o público.

\section{CONCLUSÃO}

Nesse breve estudo, pode-se constatar que o notariado brasileiro trabalha numa estrutura de monopólio ou de oligopólio, conforme a situação específica de cada comarca. Mas que essa característica, por si, não é capaz de permitir os abusos econômicos que normalmente ocorreriam, face à forte regulação e fiscalização estatal exercida sobre a atividade.

A concorrência existente no mercado notarial também não é inteiramente eliminada diante da situação de monopólio ou oligopólio aqui mencionada, embora seu exercício encontre um campo extremamente restrito de atuação. A despeito da natureza pública de tais serviços, o fato de serem exercidos em caráter privado, aliado ao fato de que os usuários dos serviços não estão vinculados a lavrar os atos de seu interesse num determinado cartório, como ocorre com os registros de imóveis, impõe ao tabelião a necessidade de buscar permanentemente o aprimoramento dos serviços prestados, aí incluída a evolução do seu próprio preparo jurídico e profissional. 
É nessa busca permanente de aperfeiçoamento, portanto, a seara principal onde, de modo reflexo, trava-se a concorrência entre os cartórios de notas. Essa concorrência, apesar de extremamente limitada quando comparada aos segmentos econômicos que trabalham em regime de livre iniciativa, pode ocorrer sem desrespeito à regulação pública existente e mostra-se indispensável para a manutenção do alto padrão de eficiência e qualidade dos serviços, verificado hoje. A correta compreensão dessa temática na análise dos serviços notariais demonstra o acerto do constituinte originário na redação do artigo 236, da Lei Maior, ao optar por manter a natureza pública dessa atividade, mas delegar seu exercício a particulares, selecionados por concurso público de provas e títulos.

\section{REFERÊNCIAS}

ARAÚJO, Lucas Bernardes; FORTES, Flávia Teixeira. O direito da concorrência e direito de propriedade intelectual. Revista Jus Navigandi, ISSN 1518-4862, Teresina, ano 14, n. 2350, 7 dez. 2009. Disponível em: <https://jus.com.br/artigos/13969>. Acesso em: 18 de janeiro de 2019.

ASCENSÃO, José Oliveira. Concorrência desleal, Coimbra: ed. Almedina, 2002

BARBOSA, Denis Borges. A concorrência desleal, e sua vertente parasitária. 2011. Disponível em:

<http://www.denisbarbosa.addr.com/arquivos/novidades/concorrencia_desleal.pdf >. Acesso em: 15 de janeiro de 2019.

BERNINI, Giorgio. Un secolo di filosofia antitrust. Bologna: Editrice, 1991.

BITTAR, Carlos Alberto. Teoria e prática da concorrência desleal. São Paulo: Saraiva. 1989.

BORJAS, George J. Economia do trabalho. 5. ed. Porto Alegre: Bookman, 2012.

BRANDELLI, Leonardo. Teoria geral do direito notarial. 2. ed. São Paulo: Saraiva, 2007.

BRASIL. Constituição da República Federativa do Brasil de 1988. Emendas Constitucionais de Revisão. Diário Oficial da União. Brasília, 5 out. 1988.

BRASIL. Lei no 8.935, de 18 de novembro de 1994. Regulamenta o art. 236 da Constituição Federal, dispondo sobre serviços notariais e de registro. (Lei dos cartórios). Diário Oficial da União. Brasília, 18 nov. 1994.

BRASIL. Resolução n.81 de 09 de junho de 2009. Dispõe sobre os concursos públicos de provas e títulos para a outorga das Delegações de Notas e de Registro, e minuta de edital. Conselho Nacional de Justiça. Brasília, 09 jun. 2009.

BRASIL. Supremo Tribunal Federal. Supremo decide que serviços notariais devem ser criados por lei. 29 jun. 2011. Disponível em: <http://www.stf.jus.br/portal/cms/verNoticiaDetalhe.asp?idConteudo=183203>. Acesso em: 20 de dezembro de 2018.

CAMPILONGO, Celso Fernandes. Direito e Democracia. $2^{\text {a }}$ ed., São Paulo, Max Limonad, 2000. 
FARIAS, Claudio V. S. Técnico em administração: gestão e negócios. Porto Alegre: Bookman, 2013.

FERREIRA, Paulo Roberto Gaiger; RODRIGUES, Felipe Leonardo. Tabelionato de notas I: teoria geral do direito notarial e minutas. São Paulo: Saraiva, 2016. (Coleção Cartórios)

FRANCISCHINI, Nadialice. Aspectos gerais sobre o direito da concorrência. Disponível em: <http://revistadireito.com/aspectos-gerais-sobre-o-direito-da-concorrencia/>. Acesso em: $15 \mathrm{de}$ janeiro de 2019.

FRANK, Robert H.; BERNANKE, Be S. Princípios de economia. 4. ed., São Paulo: Porto Alegre: Bookman, 2013.

GLÓRIA, Daniel Firmato de Almeida. A livre concorrência como garantia do consumidor. Belo Horizonte: Del Rey: FUMEC, 2003.

GONÇALVES, Antonio Carlos Pôrto. Economia empresarial. Rio de Janeiro: Editora FGV, 2012.

HUBBARD, R. Glenn; O’BRIEN, Anthony Patrick. Introdução à economia. 2. ed. Porto Alegr3e: Bookman, 2010.

LEAL, Victor Nunes. Publicações da escola da AGU: A Nova Lei do CADE - Escola da Advocacia-Geral da União Ministro Victor Nunes Leal - Ano IV, n. 19 (jul./2012).- Brasília: EAGU - mensal.

LEOPOLDINO, DA FONSECA; BOSCO, João. Lei de proteção da concorrência: comentários à legislação antitruste. Rio de Janeiro: Forense, 2001.

MATESCO, Vierene Roxo. Economia aplicada: empresas e negócios. Rio de Janeiro: Editora FGV, 2011.

MELO FILHO, Luiz Gonzaga Pereira de. Liberdade de concorrência. Revista Jus Navigandi, ISSN 1518-4862, Teresina, ano 16, n. 2991, 9 set. 2011. Disponível em:

<https://jus.com.br/artigos/19947>. Acesso em: 10 de janeiro de 2019.

MIRANDA, João Lucas Costa de. Economia e Direito econômico. Disponível em: https://joaododireito.wordpress.com/2015/10/21/economia-direito-economico/. Acesso em 05 de janeiro de 2019.

MOTA, Anderson. Estratégia competitiva. Curitiba: IESDE Brasil, 2009.

MOTTA, Massimo. Política de concorrência: teoria e prática e sua aplicação no Brasil. Rio de Janeiro: Elsevier, 2015.

NASCIMENTO NETO, José Afonso. O princípio da livre concorrência na constituição federal de 1988. 7 mar. 2009. Disponível em:

<https://www.jurisway.org.br/v2/dhall.asp?id_dh=1189>. Acesso em: 04 de janeiro de 2019. 
OLIVEIRA, Marcel Thiago de. Concorrência lícita. Revista Jus Navigandi. Teresina, ano 14, n. 2152, 23 maio 2009. Disponível em: <https://jus.com.br/artigos/12859>. Acesso em: 05 de janeiro de 2019.

PEREIRA, José Matias. Defesa da concorrência no Brasil:. Revista Jus Navigandi, Teresina, ano 9, n. 282, 15 abr. 2004. Disponível em: <https://jus.com.br/artigos/5097>. Acesso em: 20 de dezembro de 2018.

PIMENTA, Luiz José. Concorrência e lucro no mercado automotivo. Salvador, 10 ago. 2014.

SALLES, Carlos Alberto de. O Direito do Consumidor e suas influências sobre os mecanismos de regulação do mercado. Revista de Direito do Consumidor, São Paulo, n. 17, p. 85-96, jan./mar. 1996.

SALOMI, Maíra Beauchamp. O Acordo de Leniência e seus Reflexos Penais. Dissertação de Mestrado. Faculdade de Direito da Universidade de São Paulo. 2012.

SAMUELSON, Paul A.; NORDHAUS, William D. Economia. 19. ed. São Paulo: AMGH, 2012.

SILVA, Pedro Aurélio de Queiroz Pereira da. Breves linhas sobre o Direito da Concorrência. Revista Jus Navigandi, ISSN 1518-4862, Teresina, ano 15, n. 2518, 24 maio 2010. Disponível em: <https://jus.com.br/artigos/14886>. Acesso em: 20 de dezembro de 2018.

SOUZA, Simone Letícia Severo e. Das práticas concorrenciais ilícitas: as diferenças entre concorrência desleal e infração à ordem econômica. Revista de Direito Brasileira. São Paulo. 2016, p. 216.

TOIGO, Daiille Costa. Defesa da concorrência: atos de concentração. Revista Jus Navigandi, ISSN 1518-4862, Teresina, ano 15, n. 2666, 19 out. 2010. Disponível em: <https://jus.com.br/artigos/17646>. Acesso em: 22 de dezembro de 2018.

VAZ, Isabel. Direito econômico da concorrência. Rio de Janeiro: Forense, 1993. 